
D:\Nsurg\Vol. 23, No. 4, Oct. - Dec., 2019\Nsurg-5.Doc
Fig. 1-2 Color
(A)
P. $294-299$
III

ORIGINAL ARTICLE

\title{
Visual Improvement after Endoscopic Endonasal Transsphenoidal Excision of Pituitary Gland Tumor
}

\author{
ZUBAIR AHMED KHAN, HABIB SULTAN, MUHAMMAD WAQAS \\ SARFRAZ KHAN, TOQEER AHMED, ANWAR CHAUDHRY \\ Department of Neurosurgery, Postgraduate Medical Institute, Lahore General Hospital, Lahore \\ Khyber Medical University, Kohat Institute of Medical Sciences, Kohat \\ DOI: https://doi.org/10.36552/pjns.v23i4.385
}

\begin{abstract}
Objective: To evaluate the frequency of improved visual acuity after Endoscopic Endonasal Transsphenoidal excision of pituitary gland tumor.

Study Design: Descriptive case series.

Materials and Methods: In our study, Pre-operative visual acuity was noted by using the Snellen's chart. Then patients underwent pituitary gland excision though Endoscopic Endonasal Transsphenoidal approach under general anesthesia. After surgery, patients were shifted in postsurgical wards and then will be discharged from there and were examinedfor 3 months in OPD. Snellen's chart was used to evaluate patents for visual acuity after 3 months by an experienced ophthalmologist having at least 4 years residency experience If visual acuity increased $\geq 1$ line, then improved visual acuity was labeled.
\end{abstract}

Results: Improved visual acuity after pituitary gland tumor excision was seen in 59(89.39\%) patients. Age and gender of patients did not show any statistically significant association for improved visual acuity.

Conclusions: Results of this study showed that pituitary gland tumor excision through Endoscopic Endonasal Transsphenoidal approach is effective in terms of visual acuity improvement. Our main objectives in pituitary surgery are protection and reinstatement of vision and this surgical approach give maximum cover to vision restoration.

Keywords: Transsphenoidal excision, Pituitary adenoma, Visual acuity.

\section{INTRODUCTION}

Giant pituitary adenomas of fibrous consistency, excessive size and unfavorable geometric configuration can be difficult to resect through conventional operative approaches. ${ }^{1}$

Frequency of $16.7 \%$ pituitary adenomas was documented covering various groups of brain tumors.Pituitary tumors are believed to be of benign nature histologically. Though, these adenomas may increase in size leading to neurosurgical complications such as visual impairment and if not treated timely it may lead to blindness. ${ }^{2,3}$

In resection of giant pituitary adenomas, additional visualization of critical neurovascular structures can be achieved by using a transcranial component to the Transsphenoidal approach. The rates of complications are alike to other series of approaches used to resect complicated pituitary tumors. The above and below method is secure as well successful and the instant and long-lasting benefits of a single-stage approach validate its efficacy in this chosen group of patients. ${ }^{1}$

For the elimination of pituitary adenomas, Endoscopic Transsphenoidal pituitary surgery is becoming more popular. It is also widely recognized that Transsphenoidal microscopic/endoscopicresection of pituitary adenomas is broadly accepted as a wellestablished procedure that provide better results. ${ }^{4}$

$5(16.1 \%)$ and $26(83.9 \%)$ out of 31 eyes were 
reported having normal and abnormal pre-operative visual fields respectively and 22 out of these 26 were improved. ${ }^{5}$ Another study illustrated that as a result of Transsphenoidal surgery, an overall betterment of $78 \%$ in visual symptoms was recorded. ${ }^{6}$

\section{MATERIALS AND METHODS}

\section{Study Design}

This Non-probability, consecutive sampling techniquestudy was conducted at Neurosurgery department, PGMI, Lahore and Khyber Medical University, Kohat Institute of Medical Sciences, Kohat from September 2017 to October 2018 with a total duration of one year. Sixty six patients of ages between 20 to 70 years of both genders were taken in this study.

\section{Inclusion Criteria}

Patients of either gender and age in 20 to 70 years range presenting with diagnosis of pituitary adenoma (as per medical record) with visual acuity $>20 / 20$ on Snellen's chart.

Total 66 patients satisfying inclusion criterion were included from OPD of Neurosurgery, Lahore General Hospital, Lahore and Khyber Medical University, Kohat Institute of Medical Sciences, Kohat.

\section{Exclusion Criteria}

Patients with redo surgery or recurrent adenomas (on medical record), having congenital or chronic poor visual acuity before diagnosis of adenoma (medical record).

\section{Data Collection}

Informed consent was obtained. Demographic variables (name, age, gender, and duration of diagnosis) were also documented. Pre-operative visual acuity was noted by using the Snellen's chart. Then patients underwent pituitary gland excision though Endoscopic Endonasal Transsphenoidal approach under general anesthesia. After surgery, patients were shifted in postsurgical wards and then will be discharged from there and were examined for 3 months in OPD. Visual acuity was evaluated by using the Snellen's chart after months by an experienced ophthalmologist having at least 4 years residency experience. Improvement in Visual acuity was noted if visual acuity increased $\geq 1$ line. Information was collected by using prearranged proforma.

\section{Data Analysis}

Data was analyzed was SPSS Version 20 and presented in the form of charts and graphs.

\section{RESULTS}

This study was consisted on 66 patients taken in by using Non-probability, Consecutive sampling technique.

\section{Gender Distribution}

There were 34 (51.52\%) male and 32 (48.48\%) female patients.

\section{Age Incidence}

Patient's age was ranging from 20-years to 70-years with a mean of $46.26 \pm 15.46$. Mean duration for diagnosis of patients was $6.33 \pm 3.13$ months.

\section{Clinical Presentation and Treatment}

Visual acuity of patients before and after operation was noted. Improved visual acuity after pituitary gland tumor excision was seen in 59 (89.39\%) patients (Fig. $1)$.

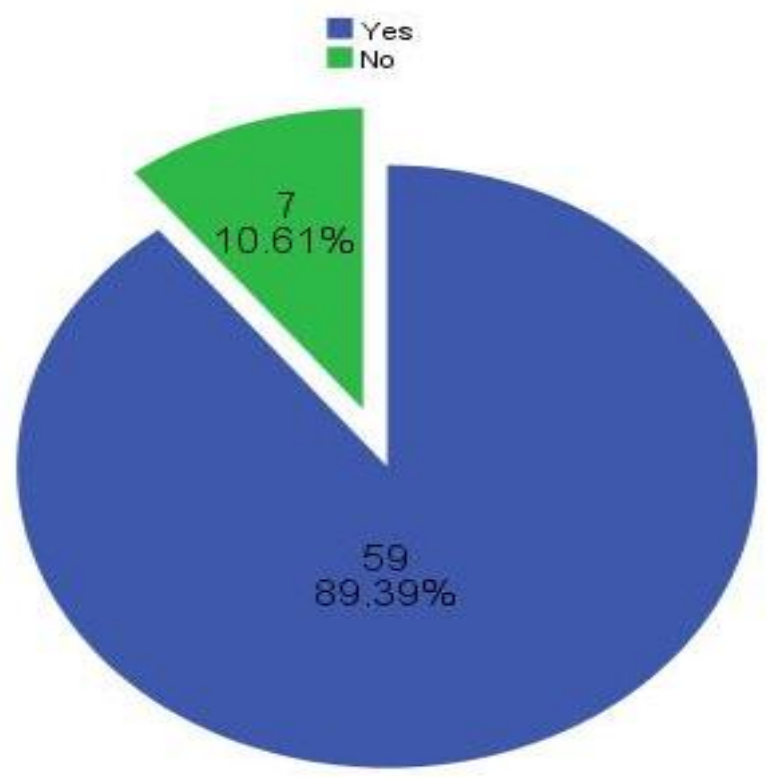

Fig. 1: Post-Excision Improvement in VA 


\section{Outcome}

No statistically significant association was seen between age groups and improvement in VA after pituitary gland tumor excision (i.e. p-value $=0.857$ ) No statistically significant association was seen between gender of patients and improvement in VA after pituitary gland tumor excision (i.e. p-value = 0.265). Duration of diagnosis of patients had no statistically significant effect on improvement in VA after pituitary gland tumor excision (i.e. p-value = 0.802). Preoperative VA had no significant effect on improvement in VA after pituitary gland tumor excision (i.e. $p$-value $=0.120$ ) .

\section{DISCUSSSION}

Pituitary adenomas accounts for $10-12 \%$ ofall brain tumors. Despite its benign nature, the mass effect on the optic chiasm and surrounding structures and the endocrinological impairment needs prompt and adequate treatment of brain tumors. Due to the benefits of being minimally invasive and providing direct approach to the pituitary gland, surgical removal by Endoscopic Endonasal Trans-sphenoidal route is more favored treatment. Several factors like the age, the preoperative visual impairment, the duration of the visual symptoms, the size of the lesion did not influence the visual outcome following excision. ${ }^{7,8}$ Ourkey goals in pituitary surgery are conservation and restoration of vision.

Visual disturbances are noted when the PA grows superiorly ahead of the sella and squeezes optic nerves anteriorly, the optic chiasm centrally, or optic tracts posteriorly. The classic presentation is a slowly progressive bitemporal hemianopia caused by pressure on nasal fibers of the chiasm. Bilateral deterioration of central visual acuity is a relatively insensitive indicator of mass effect and correlates poorly with visual deficit. However, reduced color vision is usually one of the first signs of compressive optic neuropathy. ${ }^{9}$

An abrupt hemorrhage or infarction or both within the pituitary adenoma causes pituitary apoplexy thatnormally comes with impulsivebeginning of extreme headache and visual disturbance. Besides visual loss, ophthalmologic symptoms often include diplopia due to lateral compression of cranial nerves in the cavernous sinus. Unstable or progressive visual deterioration is an indication for urgent Transsphenoidal decompression and tumor removal. ${ }^{10}$
In this study improved visual acuity after pituitary gland tumor excision was seen in 59(89.39\%) patients. Age and gender of patients did not show any statistically significant association for improved visual acuity. However, in the younger age group number of patients was higher as compared to other age groups who had improved visual acuity. For both male and female patients almost equal number of patients had improved visual acuity.Duration of disease and preoperative visuals acuity both did not show any statistically significant association for improvement in visual acuity post operatively. Successful Transsphenoidal surgery for PA usually improve visual deterioration or even restore it to normal. And there is a strong correlation between improvement of visual clarity and visual field recovery, but outcomes are not parallel in every case.

VA of $15 / 18(83.33 \%)$ patients with pituitary apoplexy had improved after early Endoscopic Transsphenoidal operation reported by Ju-Wan Seuk in his study. ${ }^{11}$ Amit Kumar Thotakura in his study reported that $42.2 \%$ of patients who underwent Transsphenoidal excision of pituitary tumor has improved visual acuity but not normalized. ${ }^{12}$ Recently in 2016 Edson Rocha Constantino reported that for the cure of large pituitary tumors, visual outcome of $32.1 \%$ of patients improved who were operated by endoscopic endonasal Transsphenoidal approach.

Our objectives in pituitary adenoma surgery is to prevent or stop progression of visual loss. In addition, patients who already lost vision from these tumors can even achieve recovery following surgery. In literature reviews visual improvement after endoscopic endonasal Transphenoidal approach for large and giant pituitary adenomas excision ranges in between $32.1 \%$ $97.7 \%^{13-20}$ respectively showing better results of endoscopic endonasal Transphenoidal approach for management of pituitary tumors in terms of visual outcome improvement.

Results of this study is consistent with the findings reported by Ju-Wan Seuk as visual improvement after surgery in his study was seen in $83.3 \%$ and in this study, it was seen in $89.39 \%$. However visual improvement after surgery reported by Amit Kumar Thotakura and Edson Rocha Constantino was quite low as compared to this study. i.e. $(42.2 \%$ \& $32.2 \%$ this study $89.39 \%$ ).

According to Cohen et al. better visual acuity outcome was seen in patients with lesser degree of preoperative visual acuity compromise. ${ }^{21}$ Gnanalingham et al. reported that the extent of the 
visual field recovery was mainly dependent on the preoperative visual field deficit. ${ }^{7}$

Sullivan et al. in their retrospective study of 45 patients concluded that the preoperative visual acuity was not predictive of postoperative visual acuity ${ }^{22}$. Powell in his series of 67 patients reported that preoperative visual defect did not correlate to the postoperative visual recovery. ${ }^{23}$

Recently in 2017 Amit Kumar Thotakura in his study reported no statistically significant correlation between the severity of preoperative visual impairment and the visual outcome. ${ }^{12}$ Agrawal and Mahapatra concluded that even if the preoperative visual impairment is severe, better visual outcome can be achieved if the duration of the symptoms is less. ${ }^{24}$ Symon et al. reported that the degree of visual improvement correlated with the size of the lesion. ${ }^{25}$

Regarding effect of preoperative visual acuity on post-operative improvement in visual acuity was variables across the study. Cohen et al and Gnanalingham et al, were agreeing that with lesser degree of preoperative visual acuity resulted in better visual acuity improvement, which contradicts the results of this study about the effect of preoperative visual outcome on postoperative betterment in visual acuity but these findings are supported by Sullivan et al, Powell and Amit Kumar Thotakura. Keeping in mind the above discussion it can be said that results of this study and results of others demonstrate that Endoscopic Endonasal Transsphenoidalhas good results withdecreased morbidity and mortality for treating pituitary adenoma.

\section{CONCLUSION}

Results of this study showed that pituitary gland tumor excision through Endoscopic Endonasal Transsphenoidal approach is effective in terms of improvement in visual acuity. As conservation and reinstatement of vision are main goals in pituitary surgery, this surgical approach has given maximum cover to the vision restoration in pituitary adenomas.

\section{REFERENCES}

1. D'Ambrosio AL, Syed ON, Grobelny BT, Freda PU, Wardlaw S, Bruce JN. Simultaneous above and below approach to giant pituitary adenomas: surgical strategies and long-term follow-up. Pituitary, 2009; 12 (3): 217-25. Doi:10.1007/s11102-009-0171-5

2. Müslüman AM, Cansever T, Yılmaz A, Kanat A, Oba E, Çavuşoğlu H, et al. Surgical results of large and giant pituitary adenomas with special consideration of ophthalmologic outcomes. World neurosurgery, 2011; 76 (1): 141-8. Doi:10.1016/j.wneu.2011.02.009

3. Ho R-W, Huang H-M, Ho J-T. The influence of pituitary adenoma size on vision and visual outcomes after trans-sphenoidaladenectomy: a report of 78 cases. Journal of Korean Neurosurgical Society, 2015; 57 (1): 23-31. Doi:10.3340/jkns.2015.57.1.23

4. Ammirati M, Wei L, Ciric I. Short-term outcome of endoscopic versus microscopic pituitary adenoma surgery: a systematic review and meta-analysis. Journal of Neurology, Neurosurgery, and Psychiatry, 2013; 84 (8): 843-9. Doi:10.1136/jnnp-2012-303194

5. Kuruvilla R, Ewend M, Senior B, Givre S. Visual Function after Minimally Invasive Pituitary Surgery (MIPS). Fax J. 2006-07: Online.

6. Elgamal EA, Osman E, El-Watidy S, Jamjoom Z, Hazem A, Al-Khawajah N, et al. Pituitary adenomas: patterns of visual presentation and outcome after transsphenoidal surgery-an institutional experience. Internet J Ophthalmol Vis Sci. 2007; 4 (2).

7. Gnanalingham K, Bhattacharjee S, Pennington R, Ng J, Mendoza N. The time course of visual field recovery following Transphenoidal surgery for pituitary adenomas: predictive factors for a good outcome. Journal of Neurology, Neurosurgery \& Psychiatry, 2005; 76 (3): 415-9. Doi:10.1136/jnnp.2004.035576

8. Svien HJ, Love JG, Kennedy WC, Colby Jr MY, Kearns TP. Status of vision following surgical treatment for pituitary chromophobe adenoma. Journal of neurosurgery, 1965; 22 (1): 47-52.

Doi:10.3171/jns.1965.22.1.0047

9. Prasad S, Volpe NJ, Balcer LJ. Approach to opticneuropathies: clinical update. The neurologist, 2010; $\quad 16 \quad$ (1): 23-34. Doi:10.1097/NRL.0b013e3181be6fad

10. Murad-Kejbou S, Eggenberger E. Pituitary apoplexy: evaluation, management, and prognosis. Current opinion in ophthalmology, 2009; 20 (6): 456-61.

Doi:10.1097/ICU.0b013e3283319061

11. Seuk J-W, Kim C-H, Yang M-S, Cheong J-H, Kim JM. Visual outcome after transsphenoidal surgery in patients with pituitary apoplexy. Journal of Korean Neurosurgical Society, 2011; 49 (6): 339-44.

12. Thotakura AK, Patibandla MR, Panigrahi MK, Addagada GC. Predictors of visual outcome with transsphenoidal excision of pituitary adenomas having suprasellar extension: A prospective series of 100 cases and brief review of the literature, 2017.

Doi:10.4103/1793-5482.149995

13. Constantino ER, Leal R, Ferreira CC, Acioly MA, Landeiro JA. Surgical outcomes of the endoscopic endonasal transsphenoidal approach for large and giant pituitary adenomas: institutional experience with special attention to approach-related complications. Arquivos de neuro-psiquiatria. 2016; 74 (5): 388-95. 
14. Cusimano MD, Kan P, Nassiri F, Anderson J, Goguen J, Vanek I, et al. Outcomes of surgically treated giant pituitary tumours. The Canadian Journal of Neurological Sciences, 2012; 39 (04): 446-57. Doi: https://doi.org/10.1017/S0317167100013950

15. Di Maio S, Cavallo LM, Esposito F, Stagno V, Corriero OV, Cappabianca P. Extended endoscopic endonasal approach for selected pituitary adenomas: early experience: Clinical article. Journal of neurosurgery, 2011; 114 (2): 345-53. Doi:10.3171/2010.9.JNS10262

16. Gondim JA, Almeida JPC, Albuquerque LAF, Gomes EF, Schops M. Giant pituitary adenomas: surgical outcomes of 50 cases operated on by the endonasal endoscopic approach. World neurosurgery, 2014; 82 (1): e281-e90. Doi:10.1016/j.wneu.2013.08.028

17. Hofstetter CP, Nanaszko MJ, Mubita LL, Tsiouris J, Anand VK, Schwartz TH. Volumetric classification of pituitary macroadenomas predicts outcome and morbidity following endoscopic endonasal transsphenoidal surgery. Pituitary, 2012; 15 (3): 45063. Doi:10.1007/s11102-011-0350-z

18. Juraschka K, Krischek B, Monsalves E, Kilian A, Ghare A, Godoy BL, et al. Endoscopic Endonasal Transsphenoidal Approach to Large and Giant Pituitary Adenomas: Institutional Experience and Predictors of Extent of Resection. Journal of Neurological Surgery Part B: Skull Base, 2013; 74 (S 01): A014.

19. Koutourousiou M, Gardner PA, Fernandez-Miranda JC, Paluzzi A, Wang EW, Snyderman CH. Endoscopic endonasal surgery for giant pituitary adenomas: advantages and limitations: Clinical article. Journal of neurosurgery, 2013; 118 (3): 621-31.

Doi:10.3171/2012.11.JNS121190

20. Nakao N, Itakura T. Surgical outcome of the endoscopic endonasal approach for non-functioning giant pituitary adenoma. Journal of Clinical Neuroscience, 2011; 18 (1): 71-5.

Doi:10.1016/j.jocn.2010.04.049

21. Cohen AR, Cooper PR, Kupersmith MJ, Flamm ES, Ransohoff J. Visual recovery after transsphenoidal removal of pituitary adenomas. Neurosurgery, 1985; 17 (3): 446-52. Doi:10.1227/00006123-198509000-00008

22. Sullivan L, O'day J, McNeill P. Visual Outcomes of Pituitary Adenoma Surgery: St. Vincent's Hospital 1968-1987. Journal of Neuro-Ophthalmology, 1991; 11 (4): 262-7. PMID:1838546

23. Powell M. Recovery of vision following transsphenoidal surgery for pituitary adenomas. British journal of neurosurgery, 1995; 9 (3): 367-74. PMID:7546358

24. Agrawal D, Mahapatra AK. Visual outcome of blind eyes in pituitary apoplexy after transsphenoidal surgery: a series of 14 eyes. Surgical neurology, 2005; 63 (1): 42-6. Doi:10.1016/j.surneu.2004.03.014

25. Symon L, Jakubowski J. Transcranial management of pituitary tumours with suprasellar extension. Journal of Neurology, Neurosurgery \& Psychiatry, 1979; 42 (2): 123-33. PMID:217970

\title{
Additional Information
}

Disclosures: Authors report no conflict of interest.

Ethical Review Board Approval: The study was conformed to the ethicalreview board requirements.

Human Subjects: Consent was obtained by all patients/participants in this study.

\section{Conflicts of Interest:}

In compliance with the ICMJE uniform disclosure form, all authors declare the following:

Financial Relationships: All authors have declared that they have no financial relationships at present or within the previous three years with any organizations that might have an interest in the submitted work.

Other Relationships: All authors have declared that there are no other relationships or activities that could appear to have influenced the submitted work.

\author{
Address for Correspondence: \\ Zubair Ahmed Khan \\ Department of Neurosurgery \\ Postgraduate Medical Institute, Lahore General Hospital \\ Lahore \\ Email:zooobby890@gmail.com
}




\begin{tabular}{|c|c|c|c|}
\hline \multicolumn{4}{|c|}{ AUTHORSHIP AND CONTRIBUTION DECLARATION } \\
\hline Sr.\# & Author's Full Name & Intellectual/Contribution to Paper in Terms of: & \multirow{7}{*}{$\begin{array}{l}\text { Signature by the } \\
\text { author(s) }\end{array}$} \\
\hline 1. & $\begin{array}{l}\text { Zubair Ahmed Khan } \\
\text { (Main/Principal Author). }\end{array}$ & \multirow{4}{*}{$\begin{array}{l}\text { 1. Performance for Study Design and Methodology. } \\
\text { 2. Data Collection and Calculations } \\
\text { 3. Analysis of Data and Interpretation of Results } \\
\text { etc. }\end{array}$} & \\
\hline 2. & $\begin{array}{l}\text { Habib Sultan } \\
\text { (2nd Author) }\end{array}$ & & \\
\hline 3. & $\begin{array}{l}\text { Muhammad Waqas } \\
\text { (3rd Author) }\end{array}$ & & \\
\hline 4. & $\begin{array}{l}\text { Sarfraz Khan } \\
\text { (4th Author) }\end{array}$ & & \\
\hline 5. & $\begin{array}{l}\text { Toqeer Ahmed } \\
\text { (5th Author) }\end{array}$ & $\begin{array}{l}\text { 5. Paper Writing, Referencing, Data Calculations } \\
\text { and Quality Insurer. }\end{array}$ & \\
\hline 6. & $\begin{array}{l}\text { Anwar Chaudhry } \\
\text { (6th Author) }\end{array}$ & $\begin{array}{l}\text { 6. Proposed Topics and Basic Study Design, } \\
\text { Methodology. }\end{array}$ & \\
\hline
\end{tabular}

Date of Submission: 21-09-2019

Date of Revision: 02-10-2019

Date of Online Publishing: 25-12-2019

Date of Print: 31-12-2019 